\section{IDENTIFICATION OF THE OCCURRENCE OF HYPONATREMIA IN HOSPITALIZED ELDERLY USING WEAK OPIOIDS}

Fernanda Alice Tanimoto ${ }^{1}$ Pollyanna Evelyn Ferreira Freitas ${ }^{2}$ Henrique Cerqueira Guimaraes ${ }^{2}$ Josiane Moreira da Costa ${ }^{3}$

\section{ABSTRACT}

Background: The use of opioid analgesics is a common practice in the clinic practice and the elderly are more sensitive to the usual doses of these analgesics. It is known that its use may lead to the development of hyponatremia, but there are few studies on this topic. Objective: To identify the occurrence of hyponatremia in hospitalized elderly patients using tramadol or codeine. Methods: Patients over 60 years old hospitalized from January to December 2013 who had a prescription of tramadol or codeine and who had serum sodium before the drug was started and up to 24 hours after treatment. The data are collected by consultation in an electronic medical record, followed by generation of a computerized report containing: age, sex, reason for hospitalization, opioid in use, period of use, date of hyponatremia examination, and results. Two groups were created: patients who used codeine, and those who used tramadol. Statistical analysis was used to identify the relative risk (RR), using the ratio of occurrence of hyponatremia in each group, after opioid use. Results: 77 patients were enrolled in the study, 52 of whom used the drug codeine, and 25 used tramadol. The mean length of hospital stay was 23.95 days. The RR of occurrence of hyponatremia between the groups, with a 95\% confidence interval, was 1.1886 (CI: 0.5751-2.4565; P: 0.6409). Conclusions: There was no statistically significant difference in the RR calculation for the occurrence of hyponatremia between the groups.

Keywords: eldery, hyponatremia, tramadol, codein.

\section{INTRODUCTION}

The increase in the life expectancy of the world population is associated with the increase in the frequency of chronic-degenerative diseases and traumatic and infectious affections, often accompanied by painful processes. ${ }^{1,2}$ In the pharmacological management of moderate and intense pain, the use of opioid analgesics is a common practice in clinical. ${ }^{3}$ These drugs are defined as morphine-like drugs including natural, semi-synthetic and synthetic substances, all acting on opioid receptors. ${ }^{4}$

Opioid analgesics act mimicking endogenous substances called endorphins, which have several functions, among them, inhibition of responses to painful stimuli, modulation of gastrointestinal, endocrine and autonomic functions, as well as influence on emotional and cognitive responses. ${ }^{5}$ These medicines are also classified by the ISMP (Institute for Safe Medication Practices)6 as potentially dangerous drugs, which are defined as those which have a high risk of causing serious harm to patients as a result of misuse. ${ }^{6}$

When considering the physiological changes in senescence, it is understood that elderly individuals are frequently more sensitive to the usual doses of these analgesics when compared to young patients. ${ }^{3}$ The most commonly observed adverse events due to the use of opioids are: drowsiness, mental confusion, dysphoria, constipation, nausea, postural hypotension, and urinary retention. ${ }^{3}$ It is emphasized that the occurrence of tachycardia, respiratory depression, confusion and delirium may also occur, which makes the use of these drugs permeated by professionals' fears of prescribing and/ or administering drugs of this class for fear of the patient developing dependence. ${ }^{7.8}$

Hyponatremia due to the use of weak opioids, such as tramadol and codeine, is an adverse event observed in clinical practice and not yet studied. ${ }^{9-12}$ Defined as a serum sodium concentration below the limits considered normal, and for most laboratories, less than $135 \mathrm{mEq} / \mathrm{L}^{13,14}$ hyponatremia may lead to the need for intensive care unit hospitalization and prolong hospital stay, which may lead to increased costs and mortality. ${ }^{14}$ The osmotic imbalance caused by this clinical condition promotes water inflow into the intracellular compartment, and the occurrence of this phenomenon in the central nervous system justifies the preponderance of neurological symptoms in patients with hyponatremia. ${ }^{14}$

Tramadol is a synthetic analogue of codeine with agonist action $\mu^{5}$, and in the international literature, there are some reports of cases of hyponatremia induced by weak opioids, mainly tramadol. ${ }^{10-12}$ In relation to codeine-induced hyponatremia, there are no conclusive studies yet to prove the pathophysiology of such adverse event. ${ }^{09,19}$ It is known that $\mu$ receptor agonist opioids can stimulate the secretion of antidiuretic hormone and thus lead to the development of hyponatremia. ${ }^{11,5}$ Another possibility for the occurrence of hyponatremia would be the stimulus for greater serotonin release, which would stimulate the secretion of antidiuretic hormone. ${ }^{15}$
1 Fundação Hemominas 2 Hospital Risoleta Tolentino Neves

3 Universidade Federal de Minas Gerais

Received: $12 / 07 / 2017$

Revised: $14 / 03 / 2018$

Accepted: 23/03/2018

How to cite this article: Tanimoto FA, Freitas PEF, Guimaraes HC e Costa JM. Identification of the occurrence of hyponatremia in hospitalized elderly using weak opioids. Rev. Bras. Farm. Hosp. Serv. Saúde, 9(1): 1-5, 2018.

Doi: $10.30968 /$ rbfhss.2018.091.002

Corresponding author: Josiane Moreira da Costa Universidade Federal de Minas

Gerais

Av. Presidente Antônio Carlos, 6627, Campus Pampulha, Belo Horizonte. CEP 31270-901. MG Brasil. josycostta2@yahoo.com.br 
In view of the scarcity of studies on the use of opioids, especially tramadol, and the occurrence of hyponatremia, the present study sought to investigate and compare the frequency of this event with the use of tramadol and codeine in hospitalized elderly.

\section{METHODOLOGY}

This is a cohort study with retrospective data collection ${ }^{16}$ on the occurrence of hyponatremia in elderly patients hospitalized with tramadol and codeine.

The study was carried out in a tertiary-level university hospital, inserted in the city health network of Belo Horizonte, MG, located in the northern region of this city. Currently, the institution is composed of 316 beds, has a computerized management system and electronic medical records. The dispensing of medicines also occurs through the computerized management system, which is performed by bar code tracking.

Patients older than 60 years old, who were hospitalized from January to December 2013, were prescribed opioid analgesics, tramadol or codeine and who had serum sodium before initiation and during the use of the opioid drug, accompanied by up to 24 hours after the end of treatment. The use of more than one opioid analgesic at the same time was characterized as exclusion criterion. The absence of serum sodium measurement before and after the start of opioid use were inclusion criteria because they allow the analysis of the outcome.

The sodium measurement performed at the institution occurred by means of the selective electrode method, with normal values being those between 135 and $145 \mathrm{mEq} / \mathrm{L}$. Thus, measurements below $135 \mathrm{mEq} / \mathrm{L}$ were considered as hyponatremia and values below $125 \mathrm{mEq} / \mathrm{L}$ were considered as severe hyponatremia.

The data collection was performed through electronic medical records, followed by generation of a computerized report with the information of interest of the patients under study: registry of use of the drugs codeine or tramadol, age, gender, serum sodium test result. The data were collected by a resident pharmacist from the Pharmacy Clinic service of the institution, previously trained. The training was conducted by a preceptor with experience in data collection for scientific research, who supervised the entire process, and had a durability of about two hours.

Patients were divided into two groups: those using codeine, and those using tramadol, followed by identification of a serum sodium measurement record before opioid use. The information for the entire hospitalization period was investigated to identify the occurrence of serum sodium measurement during opioid use, or up to 24 hours after the end of opioid use. Data was recorded in Microsoft Excel ${ }^{\circ}$ spreadsheet. Patients were coded, and serum sodium measurement results classified as normal, occurrence of hyponatremia (less than $135 \mathrm{mEg} / \mathrm{L}$ ) and severe hyponatremia (serum sodium concentrations lower than $125 \mathrm{mEq} / \mathrm{L}$ ). To better characterize the groups, it was decided to identify the occurrence of hyponatremia in each group, according to the patients' gender.

From the identification of the incidence of hyponatremia in the codeine and tramadol groups, the incidence ratio was calculated separately using the Medcalc program, available at https://www.medcalc.org ${ }^{17}$. For the description of the participants' profile, the variables International Code of Diseases (ICD), recorded at the time of admission, age and average length of stay were considered. For the group characterization and bivariate statistical analysis, we considered the opioid analgesic in use, laboratory results of serum sodium measurement before and after opioid use. The presentations of the drugs available in the institution under study are $30 \mathrm{mg}$ codeine tablets, and tramadol oral solution with $100 \mathrm{mg} / \mathrm{mL}$, and solution injectable with $50 \mathrm{mg} / \mathrm{mL}$.

The present study was previously approved by the ethics committee of the teaching hospital of the present study and the Federal University of Minas Gerais, receiving the opinions registered under the numbers 364.228 and 42681215.5 .0000 .5149 , respectively

\section{RESULTS}

In the study period, 1202 elderly patients used the analgesics codeine or tramadol in the institution, of which 864 were excluded because they did not have a sodium dose or because they had used more than one opioid analgesic at the same time. Thus, 338 patients used only a weak opioid and measured plasma sodium, of which, 77 had plasma sodium measurement before and after opioid use. Thus, 77 patients were enrolled in the study, allowing the identification of the outcome, 52 using the drug codeine (30 mg tablet) and 25 using tramadol (oral solution $100 \mathrm{mg} / \mathrm{mL}$ or injectable solution $50 \mathrm{mg} / \mathrm{mL}$ ). The mean hospitalization time of patients enrolled in the study was 23.9 days. The mean age in the group using codeine was $72 \pm$ 8.7 years, being $71.5 \pm 8.6$ years in the group using tramadol.

Figure 01 specifies the subjects included in the study, and identification of those with hyponatremia.

Table 01 presents the ICD classification of the subjects involved in the study, where the predominance of diseases of the circulatory system in both groups is identified.

Regarding the occurrence of hyponatremia, it was identified that 32\% of the patients who used tramadol developed hyponatremia, being $26.9 \%$ in the codeine group.

Table 02 specifies the sex, age and plasma sodium measurement value used to identify hyponatremia in those subjects in whom this ionic disorder was identified.

Figure 01: Flowchart on uptake and inclusion of subjects in the study.

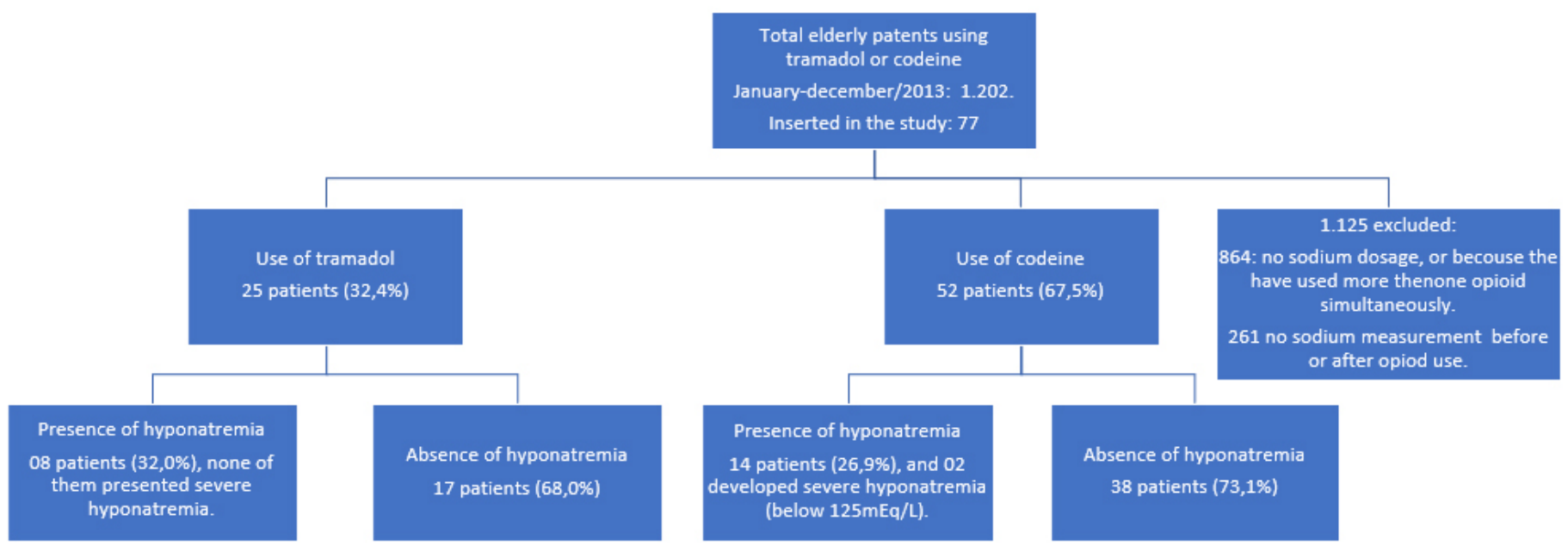


Table 01 : International Classification of Diseases at the time of admission, in the group of patients who used codeine and tramadol.

\begin{tabular}{|c|c|c|c|c|c|}
\hline CID Code Interval & CID description & \multicolumn{2}{|c|}{ Codeine } & \multicolumn{2}{|c|}{ Tramadol } \\
\hline F00-F99 & Mental and behavioral disorders & 0 & - & 1 & 4.0 \\
\hline I00-199 & Diseases of the circulatory system & 32 & 61.5 & 9 & 36.0 \\
\hline K00-K93 & Diseases of the digestive system & 0 & - & 2 & 8.0 \\
\hline L00-L99 & Skin and subcutaneous tissue disorders & 4 & 7.7 & 2 & 8.0 \\
\hline M00-M99 & Osteomuscular and connective tissue diseases & 2 & 3.9 & 0 & 0 \\
\hline N00-N99 & Diseases of the genitourinary system & 2 & 3.9 & 0 & 0 \\
\hline R00-R99 & Symptoms, signs, and abnormal findings from clinical and laboratory tests, not elsewhere classified & 2 & 3.9 & 1 & 4.0 \\
\hline
\end{tabular}

Table 02: Serum sodium score of patients who presented hyponatremia before and after opioid use (codeine and tramadol).

\begin{tabular}{|c|c|c|c|c|c|}
\hline \multicolumn{6}{|c|}{ Codeine Group } \\
\hline $\begin{array}{l}\text { Patient } \\
\text { Code }\end{array}$ & Gender & Age & $\begin{array}{l}\text { Measurement of serum sodium up to } 24 \\
\text { hours before the introduction of the opioid }\end{array}$ & $\begin{array}{l}\text { Measurement of serum sodium up to } 24 \\
\text { hours after opioid suspension }\end{array}$ & $\begin{array}{l}\text { Classification of serum sodium after opioid } \\
\text { use }\end{array}$ \\
\hline 1 & $\mathrm{~F}$ & 96 & 145.0 & 124.0 & Severe hyponatremia \\
\hline 2 & M & 67 & 141.0 & 133.0 & Hyponatremia \\
\hline 3 & M & 76 & 140.0 & 134.0 & Hyponatremia \\
\hline 4 & M & 69 & 139.0 & 132.0 & Hyponatremia \\
\hline 5 & $\mathrm{~F}$ & 78 & 138.0 & 132.0 & Hyponatremia \\
\hline 6 & M & 70 & 138.0 & 132.0 & Hyponatremia \\
\hline 7 & M & 81 & 139.0 & 134.0 & Hyponatremia \\
\hline 8 & $\mathrm{~F}$ & 84 & 139.0 & 134.0 & Hyponatremia \\
\hline 9 & M & 84 & 141.0 & 121.0 & Severe hyponatremia \\
\hline 10 & $\mathrm{~F}$ & 77 & 138.9 & 134.0 & Hyponatremia \\
\hline 11 & $\mathrm{~F}$ & 61 & 137.2 & 129.0 & Hyponatremia \\
\hline 12 & M & 63 & 137.0 & 133.9 & Hyponatremia \\
\hline 13 & M & 63 & 138.0 & 131.0 & Hyponatremia \\
\hline 14 & M & 66 & 137.8 & 131.7 & Hyponatremia \\
\hline 15 & M & 66 & 140.0 & 133.0 & Hyponatremia \\
\hline 16 & $\mathrm{~F}$ & 62 & 143.0 & 128.7 & Hyponatremia \\
\hline 17 & M & 86 & 136.0 & 131.7 & Hyponatremia \\
\hline \multicolumn{6}{|c|}{ Tramadol Group } \\
\hline $\begin{array}{l}\text { Patient } \\
\text { Code }\end{array}$ & Gender & Age & $\begin{array}{l}\text { Measurement of serum sodium up to } 24 \\
\text { hours before the introduction of the opioid }\end{array}$ & $\begin{array}{l}\text { Sodium measurement up to } 24 \text { hours after } \\
\text { opioid suspension }\end{array}$ & $\begin{array}{c}\text { Classification of serum sodium after opioid } \\
\text { use }\end{array}$ \\
\hline 1 & $\mathrm{~F}$ & 66 & 136.0 & 134.0 & Hyponatremia \\
\hline 2 & F & 78 & 140.0 & 131.0 & Hyponatremia \\
\hline 3 & M & 76 & 137.0 & 127.0 & Hyponatremia \\
\hline 4 & F & 82 & 139.0 & 131.0 & Hyponatremia \\
\hline 5 & M & 70 & 139.5 & 134.7 & Hyponatremia \\
\hline 6 & F & 70 & 141.0 & 133.0 & Hyponatremia \\
\hline 7 & M & 85 & 141.0 & 133.0 & Hyponatremia \\
\hline 8 & M & 61 & 136.4 & 128.7 & Hyponatremia \\
\hline
\end{tabular}

M: Male; F: Female 
Cases of severe hyponatremia (less than $125 \mathrm{mEq} / \mathrm{L}$ ) were detected only in the group that used codeine, whose incidence was 0.04 .

When assessing the relative risk (RR) of occurrence of hyponatremia between the groups, considering a 95\% confidence interval, an RR of 1.1886 was identified (IC: 0.5751-2.4565; P: 0.6409), without, however, statistical significance.

\section{DISCUSSION}

No statistically significant difference was observed in the analysis of the risk of incidence of hyponatremia in the group using tramadol in relation to the codeine group. Thus, in the present study, it was not identified that elderly patients hospitalized with tramadol are at higher risk of presenting hyponatremia when compared to those who used the drug codeine.

However, when analyzing the incidence of hyponatremia incidence between the groups, an average incidence of $29.45 \%$ is identified, which suggests not only that the occurrence of hyponatremia was frequent in the study population, but also that this monitored in both groups.

The prevalence of hyponatremia is greater in groups that present greater fragility, such as hospitalized, elderly patients and perioperative with fracture. In addition, the occurrence of multiple comorbidities, use of polypharmacy and increased risk of dehydration are factors that also contribute to the occurrence of hyponatremia. ${ }^{18}$

Among the main causes of electrolyte imbalances, especially hyponatremia, are medications. They can affect homeostasis (balance water and ions) or increase the secretion of the antidiuretic hormone $(\mathrm{ADH})$. The main drug classes that have hyponatremia as an adverse reaction are: antipsychotics, antidepressants and opioids. ${ }^{19}$

Cases of severe hyponatremia were only found in the codeine group (prevalence $=0.04$ ). In these situations, cases of severe hyponatremia $(\mathrm{Na}<125 \mathrm{mEq} / \mathrm{L})$, the patient may present neurological symptoms that may result in complications such as encephalopathy, non-cardiogenic pulmonary edema, seizures, coma, and death. ${ }^{18}$ Therefore, it is understood that, due to the clinical necessity of the patients, immediate replacement of ions and evaluation of the agent causing the reaction is necessary in order to take the appropriate measures.

We also identified a significant number of patients who were excluded from the study because of non-identification of serum sodium monitoring. This data suggests the need to implement actions aimed at sensitizing health professionals about the need to perform serum sodium monitoring in individuals who present a higher risk of occurrence of this undesirable clinical event, such as the elderly, and those in use of drugs that potentiate hyponatremia.

A previous study in the hospital under study identified a higher prevalence of the use of the weak opioids by the hospitalized elderly attending a clinical pharmacy service, being the predominant use of tramadol (55.9\% of the total). ${ }^{20}$ This data also points to the frequent use of opioids in the study population, and the need for monitoring. In this case, it is understood that the clinical pharmacist should also act in order to alert other health professionals about the importance of monitoring serum sodium in patients at higher risk.

When evaluating the main cause of hospitalization through the ICD10, although the present study does not allow extrapolation of the data, it is verified that in both groups diseases of the circulatory system were predominant. It is known that diseases of the circulatory system are among the main causes of hospitalization and mortality in the world population, mainly among the elderly. About $40 \%$ of the elderly aged $65-74$ years old and $60 \%$ over 85 years have the cause of mortality related to vascular diseases. ${ }^{21}$

In addition, most of the patients participating in the study had pressure ulcer, diabetic foot and thromboembolic events, which generate intense discomfort due to pain, requiring administration of opioids to obtain analgesia.

In cases of hyponatremia identification, its occurrence is considered a suspected adverse event related to the use of the medications. For the classification of adverse drug events, the Naranjo algorithm, which is a very useful tool in the area of pharmacovigilance, is usually used, and it classifies the reactions according to causality, being: definite, probable, possible and doubtful. ${ }^{22}$
However, as the present study did not contemplate the identification of the possible suspension of the opioid after the occurrence of hyponatremia, and new occurrences of this disorder if it was necessary to introduce this drug, it is not possible to identify the classification as defined according to the Naranjo algorithm. ${ }^{22}$ In addition, possible interferences of other factors were analyzed, such as the use of other medications that could lead to hyponatremia, or the existence of additional clinical complications that favored this condition.

This study has the limitation of using data recorded in medical records, and the request for laboratory measurement of serum sodium, as well as the choice of prescription of tramadol or codeine drugs, may have been influenced by specific characteristics of the physicians who did it, such as experience and/or professional training, among others. In addition, it was not possible to establish an association between the prescribed dose and the occurrence of hyponatremia.

Another limitation of the study is the impossibility of investigating possible confounding factors such as clinical specificities of the patients under study that could interfere with the occurrence of episodes of hyponatremia, and it is not possible to state that these episodes occurred solely due to the use of opioids.

The considerable number of patients excluded from the study because they used opioids and did not have serum sodium measurements also presented a limitation, as it caused the insertion of a small number of patients, which contributed to the absence of statistically significant findings. Although the present study has proposed the identification of the risk of hyponatremia occurring in the elderly who used weak opioids, other factors should be analyzed when opioids are chosen, such as the risk and benefit of other adverse reactions, considering the clinical specificities of each patient.

When considering the importance of this topic for the clinical safety of hospitalized elderly, it is recommended to carry out broader studies that address this issue, and which may contribute to the reorientation of clinical practices related to the choice of opioid to be administered in the elderly, and occurrence of hyponatremia.

\section{CONCLUSIONS}

The study identified similar percentages of patients who presented hyponatremia in both groups, and no statistically significant differences were identified in the calculation of the risk of hyponatremia with tramadol when compared to codeine use. The present study does not allow extrapolation of the data, and it is advisable to carry out more extensive studies.

\section{Finalcial Source}

We thank the institutional support of the Hospital Risoleta Tolentino Neves and the Multiprofessional Residency Program in Health of the Elderly of the Hospital das Clínicas of UFMG.

\section{Conflict of Interests}

There are no conflicts of interest.

\section{Authors' Contributions}

JMC, FAT and PEFF: Design and design or analysis and data interpretation. JMC, HCG, PEFF: Article writing or critical review relevant intellectual content. JMC and HCG: Final approval of the version to be published. JMC and FAT: All aspects of the work in ensuring the accuracy and integrity of any part of the work.

\section{Acknowledgments}

We thank Dr. Mônica Aparecida Costa and Marli Antunes for their support in the development of the project. 


\section{REFERENCES}

1. Nóbrega OT, Karnikowski MGO. A terapia medicamentosa no idNóbrega OT, Karnikowski MGO. A terapia medicamentosa no idoso: cuidados na medicação. Ciência \& Saúde Coletiva, 2005, 10 (2): 309-3013.

2. Dellaroza MSG, Furuya RK, Cabrera MAS, et al. Caracterização da dor crônica e métodos analgésicos utilizados por idosos da comunidade. Rev. Assoc. Med. Bras. 2008, 54(1): 36-41.

3. Gomes JCP, Teixeira MJ. Dor no idoso. Rev. Brasileira de Medicina, 2006, 63 (11): 554-563.

4. Duarte DF. Uma breve história do ópio e dos opióides. Rev. Bras. Anestesiologia, 2005, 55(1): 135-146, 2005.

5. Brunton LL, Lazo JS, Parker KL. Goodman \& Gilman As Bases Farmacológicas da Terapêutica. $11^{\text {a }}$ ed. Rio de Janeiro, McGraw Hill : 2006, p. 487-526.

6. Institute for Safe Medication Practices. ISMP list of high-alert medications. Huntingdon Valley (PA): ISMP: 2012. Disponível em: http://www.ismp.org/Tools/highalertmedications.pdf

7. World Institute of pain. Consensus Statement Opioids and the Management of Chronic Severe Pain in the Elderly: Consensus Statement of an International Expert Panel with Focus on the Six Clinically Most Often Used World Health Organization step III Opioids (Buprenorphine, Fentanyl, Hydromorphone, Methadone, Morphine, Oxycodone). Pain Practive, 2008, 8: 287-313.

8. PHYSICIANS FOR RESPONSIBLE OPIOID PRESCRIBING ORGANIZATION. Cautious, Evidence-Based Opioid Prescribing. Disponível em: www.responsibleopioidprescribing.org.

9. Fournier JP, Yin H, Nessim SJ et al. Tramadol for Noncancer Pain and the Risk of Hyponatremia. The American Journal of Medicine, 2015, 128 (4):418-425.

10. Abadie D, Durrieu G, Roussin G et al. "Serious" adverse drug reactions with tramadol: a 2010-2011 pharmacovigilance survey in France. Therapie, 2013, Mar-Apr, 68(2):77-84.

11. Lota AS, Dubrey SW, Wills P. Profound hyponatraemia following a tramadol overdose. QJM: An International Journal of Medicine, 2012, 105(4):397-8.

12. No authors listed. "Weak opioid analgesics. Codeine, dihydrocodeine and tramadol: no less risky than morphine. Prescrire Int., 2016, 25(168):45-50.

13. Rocha PN. Hiponatremia: conceitos básicos e abordagem prática. J. Bras. Nefrol., 2011, 33(2): 248-260.

14. Abreu F, Sousa FT, Prata MM. Hiponatremia: abordagem clínica e terapêutica. Medicina Interna, 2001, 8(11):37-48.

15. Sarret D, Le Berre JP, Zemraoui N. Tramadol - Induced Hyponatremia. Am J Kidney Dis.,2008, 52 (5) :1026.

16. Hochman B, Nahas FX, Filho RSO et al. Desenhos de pesquisa. Acta Cirúrgica Brasileira, 2005, 20 (2): 2-9.

17. Medcalc software. Disponível em: https://www.medcalc.org/calc/.
18. Cumming K, Hoyle GE, Hutchison JD, et al. Prevalence, Incidence and Etiology of Hyponatremia in Elderly Patients with Fragility Fractures. PLOS ONE, 2014, 9 (2): 1-8.

19. Gosh M, Joosten-Gstrein B, Heppner HJ, et al. Hyponatremia in Geriatric Inhospital Patients: Effects on Results of a Comprehensive Geriatric Assessment. Gerontology, 2012, 58: 430-440.

20. Ribeiro HSS, Costa JM. Acompanhamento farmacoterapêutico de idosos em uso de nalgésicos opioides em um hospital de ensino. Rev. Bras. Farm. Hosp. Serv. Saúde, 2015, 06(11): 18-23.

21. Akushevich I, Kravchenko J, Ukraintseva S, et al. Circulatory Diseases in the U.S. Elderly in the Linked National Long-Term Care SurveyMedicare Database: Population-Based Analysis of Incidence, Comorbidity, and Disability. Res. Aging, 2013, 23: 437-458.

22. Naranjo CA, Busto U, Sellers EM, et al. A method for estimating the probability of adverse drug reactions. Clin. Pharmacol. Ther., 1981, 30 (2):239-45. 